2

3

4

5

6

7

8

9

10

11

12

Abstract

Waiting times in Accident and Emergency (A\&E) Departments are a key performance indicator for the UK National Health Service (NHS) and are linked to medical decision making. We use the concept of medical disposal to consider the ways in which patients' medical problems are remoulded and transformed into a solvable problem enabling what he refers to as 'medical disposal'. Drawing on a study of 16 video-recorded cases from a single A\&E Department in the UK, collected in 2014 and 2015, conversation analysis is used to explore how options for disposal (referral and discharge) are constructed and received in interactions between junior doctors and consultants. We consider the potential impact of information imbalances between junior doctors and consultants, as well as orientation to organisation goals in the form of standardised procedures and guidelines and constraints on time. In this way we demonstrate the interactional delicacy of discussions between junior doctors and consultants concerning moving patients on from A\&E. We show how when juniors discuss cases with consultants the resultant decision making may be viewed as co-constructed. We make a case for detailed and nuanced understanding of interactions in $A \& E$ departments in order to understand the complexity of decision-making in this highly politically visible setting.

\title{
KEYWORDS
}

UK, Emergency medicine, decision making, conversation analysis 
Introduction

The problem

Waiting times are a key performance metric for the UK National Health Service (NHS). A key target is waiting times in relation to emergency care. The NHS constitution sets out that a minimum of 95 per cent of patients attending an accident and emergency (A\&E) department in England must be seen, treated and then admitted or discharged in under four hours. Waiting times in A\&E departments are never far from the headlines in the UK (http://www.independent.co.uk/news/uk/home-news/a-e-patients-waiting-times-nhs-england-12hours-10546-per-cent-royal-college-emergency-medicine-a7962941.html) and are often presented as a proxy for the health of the NHS more generally.

Analysis from the Kings Fund (2017) indicates that waiting times have been increasing over time. The causes and possible solutions are complex as A\&E performance is dependent on the operational processes and capacity of other hospital departments as well as other parts of the health and social care system. In addition to organisational and structural explanations, there has been some focus on junior doctors as 'front-line decision makers' (Adams et al 2017), alongside the contention that they reduce the progress of patients through A\&E (Sen et al 2012, Christmas et al 2013). However studies generally rely on statistical analysis of single Emergency departments as opposed to detailed analysis of clinical decision making in practice. In this paper we draw on video-recorded interactions in order to consider the interactional work done by junior doctors and consultants to construct decisions. First we define what we mean by junior doctors.

In the UK medical graduates enter the medical workforce as 'junior doctors' on a two year work based training programme. This clinical training for qualified doctors bridges the gap between 
medical school and specialty training. Completion of the first year results in full registration with the General Medical Council and completion of the second year makes junior doctors eligible for further study and training in a specialised area of medicine, such as emergency medicine. Specialty training for doctors can take up to eight years depending on the speciality and during this time they are still considered 'junior doctors' and work under the supervision of a more senior doctor, usually a consultant (British Medical Association 2017).

Both consultants and junior doctors are subject to multiple and wide ranging agendas. Junior doctors as a training grade are under pressure to grasp practical skills as well as a working knowledge of the procedures necessary for medical practice in fast paced environments such as $\mathrm{A} \& \mathrm{E}$, this is in addition to developing the self-assurance and skills to be confident decision makers. In the UK, junior doctors' training has undergone radical change and has been affected by a reduction in hours worked following the European Working Time Directive (http://www.bma.org.uk/support-at-work/ewtd/ewtd-juniors). As a result junior doctors are under pressure to gain appropriate and sufficient experience in fewer hours than was the case when their senior colleagues were themselves junior doctors. This has inevitably led to disquiet about the impact on the balance between training and service (Derrick et al 2006). It has also led to junior doctors' decision-making abilities being called into question (Bull at al 2013). Bull et al's study (2013) reported that: There was a tension for junior doctors between making their own decisions (and thereby Consultants, for their part, need to support junior doctors in their development and learning whilst 
In this paper we argue for a nuanced approach to understanding the complexity of factors underlying decision making in A\&E. We focus on interactions between junior doctors and consultants in the journey towards referral or discharge presenting this as a key site for understanding medical decision making as a distributed (Rapley 2008) and for the display of the complexity of contingencies on decisions.

The analysis employs the critical lens provided by Berg's (1992) work on medical disposals. It also draws on the idea of epistemics as outlined in the work of Heritage (2012). Focusing on interactions between junior doctors and consultants, we consider how competing demands on all doctors are managed in the everyday work of an A\&E department.

Initially we assess the usefulness of the notion of medical disposals, as explored by Berg, and its applicability to medical practice in A\&E. We also briefly outline Heritage's work on how epistemics operate in interactions in order to provide an additional position from which to consider the complexities of, and potential tensions contained within, interactions between junior and consultants in A\&E.

\section{Medical disposal}

In his classic paper on medical disposal Berg (1992) suggests that when transforming a patient's problems into solvable problems the problems are not simply translated but are remoulded. Such a transformation does not just require doctors to combine 'cognitive' items together, but rather to actively articulate an array of heterogeneous elements alongside the transformation. A problem is solvable when the doctor is able to propose a disposal; a limited set of actions which are perceived to be a sufficient answer (at this time and place) to a specific patient problem. This could take the form of, for example, a prescription, referral or advice. Thus, the physician makes the problem solvable by reducing the infinite array of possible actions to just one disposal. Key to this is the idea that historical and examination data as well as medical criteria and disposal options are not 'givens' 
which unidirectionally lead the physician towards a disposal. Importantly, the physician does not passively solve a puzzle with pre-set pieces; in articulating elements to the transformation they are actively moulded and re-constructed so as to fit a certain transformation. So what counts as the solution of the patient's problem is a result of the outcome of the transformation; and equally, what counts as the original problem is redefined during this process.

Berg (1992), in keeping with other work which considers decision making in consultations (c.f. Stivers 2007, Heritage and Maynard 2006, Collins et al 2005, Toerien 2013, Stevenson et al 2000), focuses on communication between patients and doctors. The focus in this paper is on interactions between consultants and junior doctors. Decision making relies on clinical as well as experiential expertise. Experiential expertise comes both from experience with patients but also experience with, what Berg (1992) refers to as, the routines that facilitate medical action and realise an 'economy of effort'. In this paper we employ a micro analytic interactional approach in order to understand the complexities of the ways in which consultants and junior doctors negotiate the movement of patients on from A\&E.

\section{Epistemics in interactions between consultants and junior doctors}

When considering how medical disposals are constructed it is important to consider the potential impact of information imbalances between junior doctors and consultants in the organisation of conversational sequences. Heritage (2012) introduces the idea of epistemic status to consider the relative positioning of actors in recognising one another to be more or less knowledgeable concerning some domain of knowledge. This, he argues, exists and therefore operates as a more or less settled fact. In the work presented here, junior doctors have knowledge of the patient as they have spoken to and examined them, while consultants have greater knowledge in relation to medical practices and understanding of hospital procedures. In this way we can see that epistemic 
status can be altered from moment to moment relative to the interactional contributions at any one time.

Heritage (2012) also introduces the idea of epistemic stance which concerns how speakers position themselves in relation to epistemic status in and through the design of turns in talk. He argues this additional concept is necessary because epistemic status can be dissembled by persons who deploy epistemic stance to appear more, or less, knowledgeable than they really are.

Focus of the work

In this paper we draw on 16 video-recorded cases in order to consider the interactional work done by junior doctors and consultants to construct medical disposals. We focus in particular on how options for disposal are constructed and received. We also explore the effects of organisation

127 factors such as standardised procedures and guidelines and the constraints of time. Overall the analysis works to demonstrate the interactional delicacy of discussions between consultants and junior doctors, and the orientation of both parties to epistemic status and stance when working to move patients on from A\&E.

Methods

This paper draws on ethnographic fieldwork conducted in an A\&E department in the South East of England between 2014 and 2015. The aim was to consider junior doctors' decision making. Following the award of ethical approval from an NHS ethics committee, we undertook observations by shadowing doctors at all grades to understand the setting. We also conducted informal interviews with administrative, nursing and medical staff about the work of the unit and ideas about

137 how best to conduct the work. Finally we collected a series of video-recorded cases by shadowing a junior doctor as they dealt with a single patient, following them through encounters with the 
patient, their companions, consultants, and other professional staff. Over a six month period of fieldwork 16 patient cases were recorded. All but one of the cases involved discussion with a consultant.

142 Eight junior doctors participated in the study and nine different consultants. Five of the junior doctors were in their second year of postgraduate 'foundation years' training (FY2's) and were working in A\&E on a three month rotation, two were clinical fellows and one was in their first year of training as a specialist in emergency medicine. The clinical fellows had a number of years' experience as qualified doctors but had not yet committed to a speciality. Eight of the consultants were consultants in emergency medicine and we recorded one interaction with a consultant geriatrician.

Each case involved video recordings of the junior doctor's initial consultation with a patient and video recordings of any conversation between the junior doctor and a consultant and / or other professional staff. Although there was usually more than one consultant working at any one time there was always a 'consultant in charge' to whom junior doctors would formally report to on each shift.

Two static video cameras were used to record consultations with the patient. A small handheld camera, about the size of a mobile telephone, operated by the researcher, was used to record other interactions. Additionally, junior doctors wore a lapel microphone that was attached to an audio recorder that they carried in their pocket.

Full verbatim transcripts were completed for all cases, and detailed Conversation Analytic transcriptions based on the Jeffersonian transcription system (Jefferson 2004) were made for some patient consultations and all the interactions between junior doctors and consultants. The symbols used are shown in figure 1. All the analysis presented in this paper is based on data from interactions between junior doctors and consultants. 
The research clearly involves substantial ethical issues regarding the potential impact on the conduct of care, the protection of patient and health care professional anonymity and the recording and retention of sensitive data. We argue that although the participants recorded may have reacted to the use of the recording equipment, in particular the camera, we feel any reaction will have been of significantly less magnitude in comparison to studies using interview methods where researchers have "an active and ongoing part in soliciting reports" (Potter \& Shaw, 2018: 189). We have written elsewhere (Stevenson et al 2015) on the ethical dilemmas of this research and we will not discuss this in any detail here. All participants were given a range of options in relation to sharing the data collected which ranged from using anonymised extracts to sharing original data for the purposes of education and research. All of the data presented here has been anonymised, as has the institution being discussed.

We employed conversation analysis in order to consider how actions are constructed and produced in interaction (Drew et al 2001). The focus is the construction of interactions between consultants and junior doctors when making decisions about patient care. The analysis focuses in particular on the ways in which interactions between junior doctors and consultants are constructed to lead to medical disposal (discharge from the hospital or referral to another medical specialty). Specifically the data are organised according to (i) how transformation into medical disposal is achieved and (ii) the role of epistemics in shaping interactions around medical disposal. In this way we are able to demonstrate and explore the interactional delicacy and complexity of actioning a medical disposal in A\&E. 
By far the most common scenario in our data is characterised by the junior doctor presenting their account and the consultant either explicitly or implicitly providing a summary which initiates a move towards disposal. It is useful here to consider what is known about the structure of medical consultations. Robinson (2003) argued:

the establishment of new medical problems in acute visits makes relevant an organized structure of social action that is composed of an ordered series of medical activities: establishing the reason for the visit, physicians gathering additional information (i.e., history taking and physical examination), physicians delivering diagnoses, and physicians providing treatment recommendations. This "project" of medical activity shapes physicians' and patients' understanding and production of communicative behaviour (Robinson 2003: 27).

We argue that in interactions between junior doctors and consultants the junior doctor acts as a proxy for the patient in presenting the reason for the patient's attendance at A\&E (problem presentation). Junior doctors then shift to report their actions in the form of a summary of history taking and the findings of any physical examinations. In these phases the junior doctor generally dominates the interactional space as they are in a position of greater knowledge about the experience of the individual patient (this is explored in more detail in the next section on epistemics). In this way the junior doctor can be seen to be doing the interactional work of transforming what the patient has reported and they have themselves observed through questioning and examination into a format which enables a remoulding of the patient's story into a solvable problem. The next phrase relates to the move towards delivery of a diagnosis and recommendation for action (medical disposal). In the majority of our cases the shift from 

initiated by the consultant.

In the following extract the junior doctor, in their role of proxy for the patient, reported a range of supplemented with information about a previous diagnosis of a heart problem and labyrinthitis. The complexity of the patient's problems was transformed by the consultant into the following summary which focuses on cough as the main problem, relegating loose stools and vomiting to the status of associated problems.

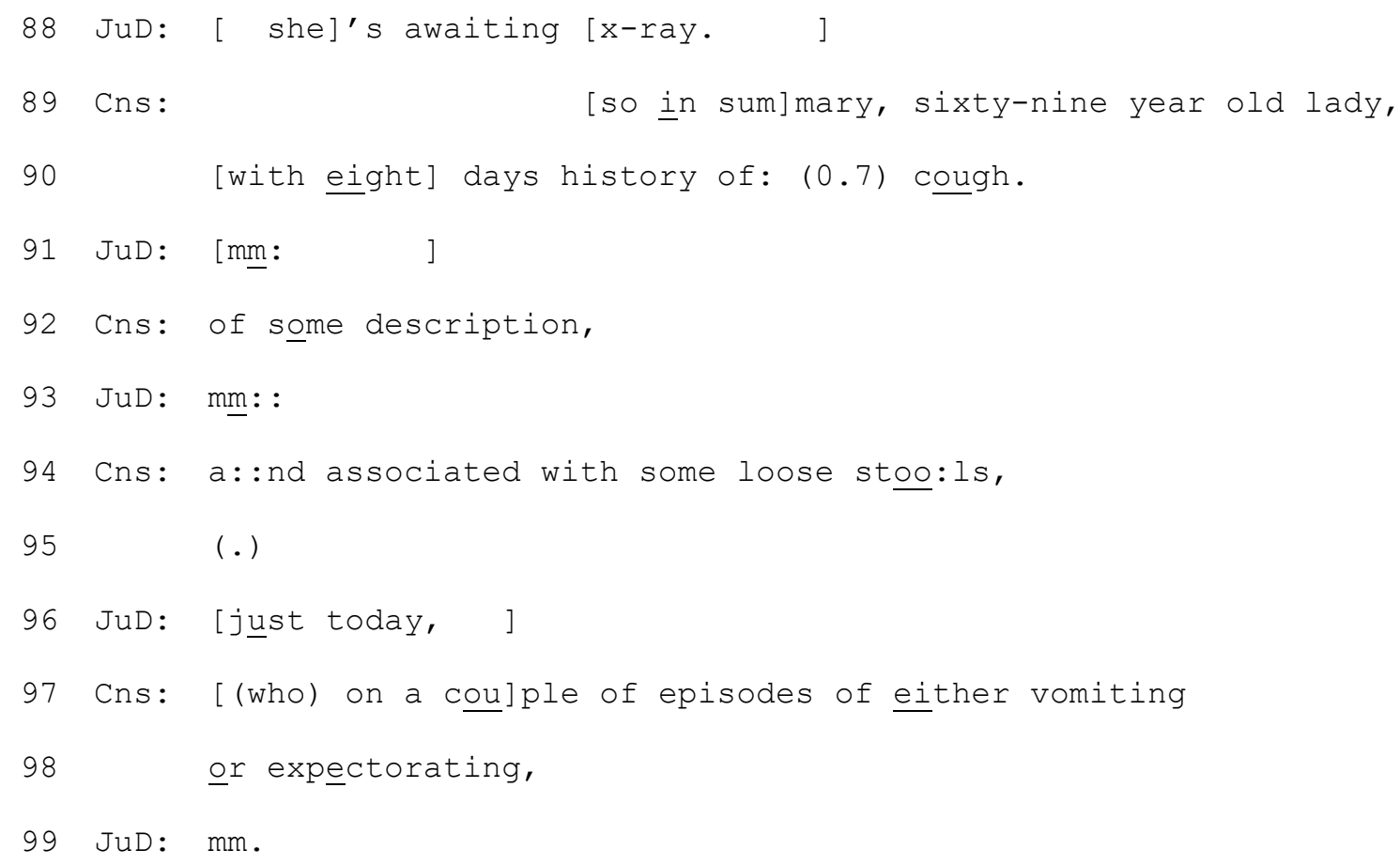
The move towards a solvable problem is marked in line 89 by the words 'so in summary' delivered by the consultant in overlap with the junior doctor. The phrasing and words used mark this as a medical pronouncement and the junior doctor provides minimal receipt responses. The junior doctor's attempt to provide more information in line 96 is produced in overlap with the consultant 
and the consultant maintains the interactional floor. In this way the consultant successfully achieves a shift in the interaction from the phase of gathering information towards the construction of options for medical disposal.

However shifts from presentation of the medical problem towards options for disposal were not always initiated by consultants. In the following extract the junior doctor can be seen to present an assessment of her thoughts on the possibilities associated with the presenting problem, finishing her conversational turn with an extended 'so'. This marks the end of her current turn and provides an interactional space for a contribution from the consultant.

\section{Extract 2, Case 3}

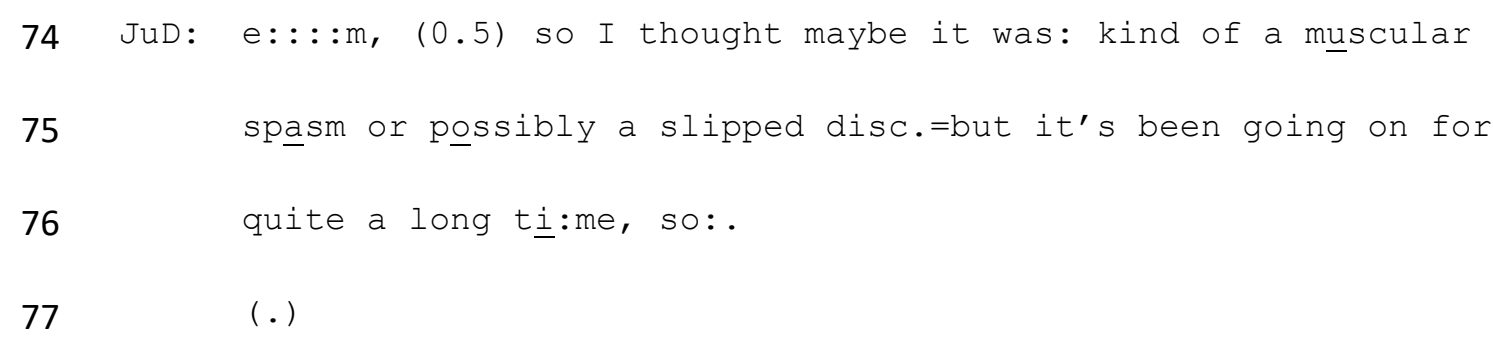

The introduction of a potential candidate diagnoses in lines 74-75, followed by an extended 'so' issued by the junior doctor in line 76 and a pause at line 77 is suggestive of a move to get the consultant to contribute at this point. Until here, aside from one question about whether there were any urinary symptoms, the consultant had only contributed continuers such as okay, yes and $\mathrm{mhm}$. Thus the junior doctor marks this as a transition point in the interaction towards the remoulding of the patient's signs and symptoms into a solvable problem which can then be used to evidence a medical disposal. 
Regardless of who makes the initial move towards the construction of a medical disposal it is important to note that generally directives towards action were presented somewhat tentatively as advice and included aspects of mitigation. So if we continue with case 3 we can see that although the consultant's talk is recognisable as building a case to support a suggested medical disposal, the talk itself is notable for its construction in terms of suggestion and mitigation.

247

Extract 3 Case 3

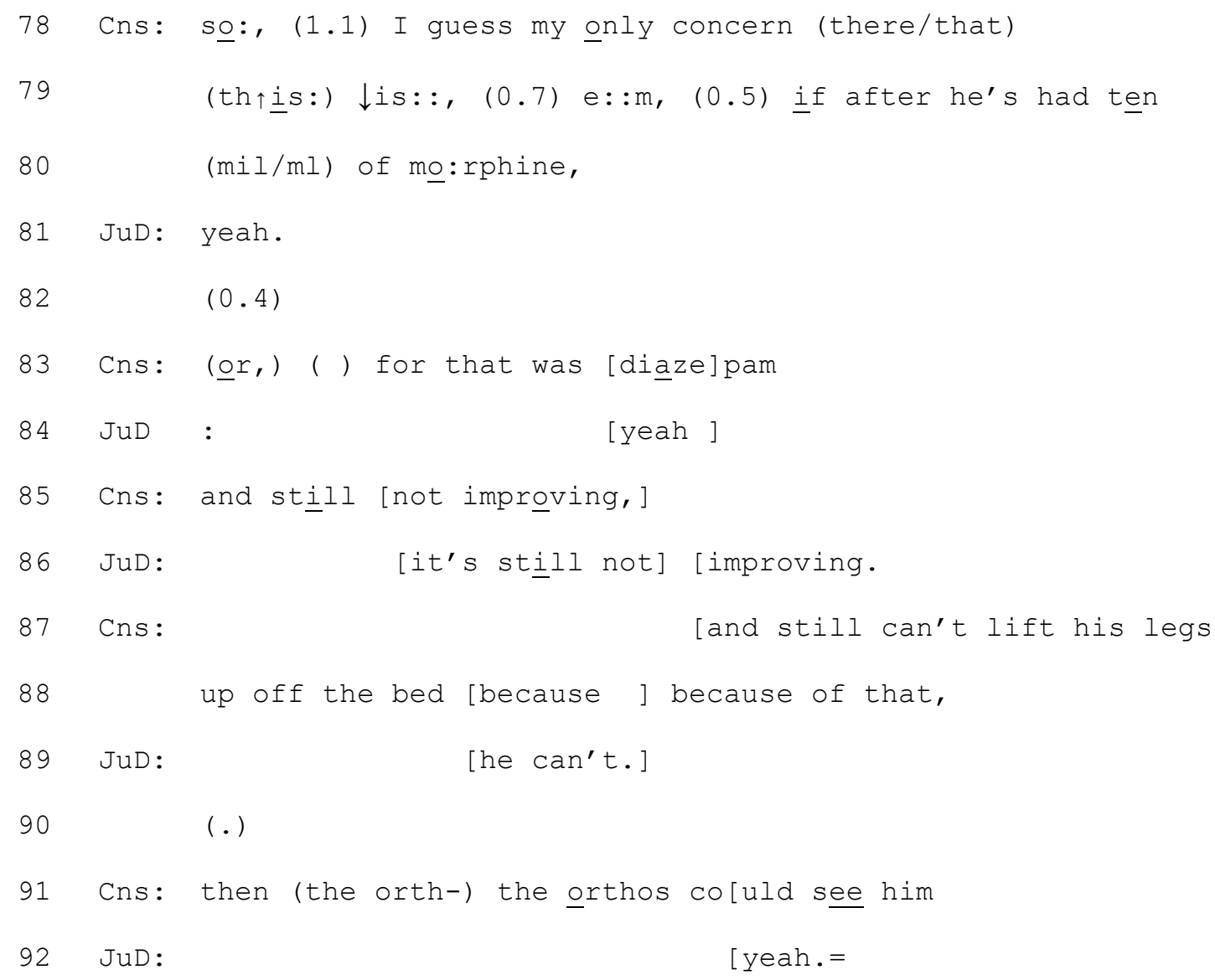

250 The consultant starts in line 78 with so: and a pause indicating disaffiliation with the junior doctor's 251 previous turn. The interaction then shifts towards pain and mobility as the focus of interest. In this

252 way the consultant shifts the topic from diagnosis which was the focus of the immediately preceding 
junior doctor's talk (see extract 2) towards medical disposal and moving the patient out of A\&E with the suggestion of a referral to the orthopaedic team (line 91). The role of 'so' in implementing incipient actions in this way has been previously noted by Bolden (2009). It is worth commenting on how the move from symptom presentation to medical disposal is constructed here. As a senior doctor, from whom advice was sought, arguably the consultant could have briefly stated that the account of pain given by the patient indicated the necessity for a referral. Instead, after marking the topic shift with so: and a pause he constructs a case for a referral to the orthopaedic team around his 'only concern' (line 78) being the lack of improvement and function of the patient in relation to the amount of pain relieving medication received (lines 78-91). Over 13 lines the consultant builds a case for referral based on the junior doctor's account of pain restricting the patient's mobility. In this way the consultant can be seen to be actively moulding and transforming the information provided by the junior doctor in order to construct evidence for a particular disposal. order a scan. This is followed by a move on the part of the junior to close the interaction. The consultant however starts on a trajectory towards medical disposal by alluding to the amount of time the patient has been in A\&E and the possibility of referral to a standardised medical pathway. 
234 JuD: Yes

235 Cns: (erm?) two: (0.5) three: : : were coming up to three hours

236

$(0.3)$

$237 \mathrm{JuD}: \quad[\mathrm{mmm}]$

238

Cns: [>depending on how] quickly: $<$ they $<$ do: : [it $>$

239 JuD:

$[\mathrm{mmm}$

240

Cns: he might be a candidate for th:e >renal colic see dee you

241

( (CDU) ) pathway<

242 JuD: okay

243 Cns: but (.) >if you can get< (.) the request on: (.) and ring the

245 JuD: ye[ah

246

Cns: [see if we can get him (.) turned arou::nd (.)

247 JuD: perfec [t

272 In lines 227-231 an agreement is reached about the actions to take and the junior doctor moves to close the encounter with an appreciation (line 231). The consultant reopens the dialogue with "erm" in overlap with the junior doctor's talk and the phrase 'tick tock tick tock' (line 233). Despite the apparent obliqueness of the talk this was received by the junior doctor with a positive affirmation, "yes" indicating her understanding of the importance of time. The talk that follows orientates more directly to the need to move the patient on from A\&E, preferably within four hours, and whether this can be achieved here by referral to a specialist care pathway. The interaction is framed as determined from the perspective of institutional structures and requirements, rather than 

proposed clinical pathway the interaction shifts to the use of medical protocols to obtain the best outcome for the patient as a person.

283

284 Extract 5, case 2

285

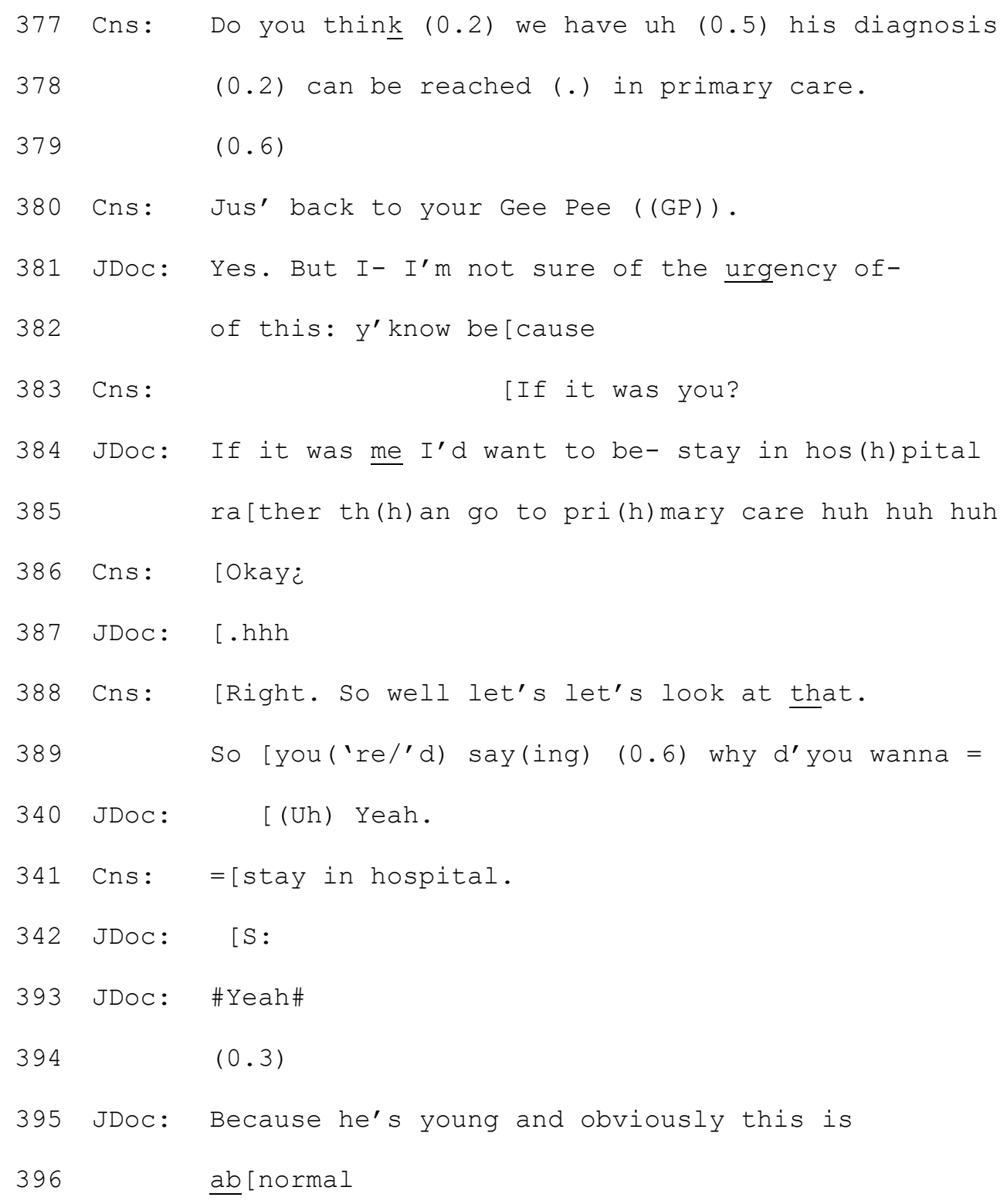




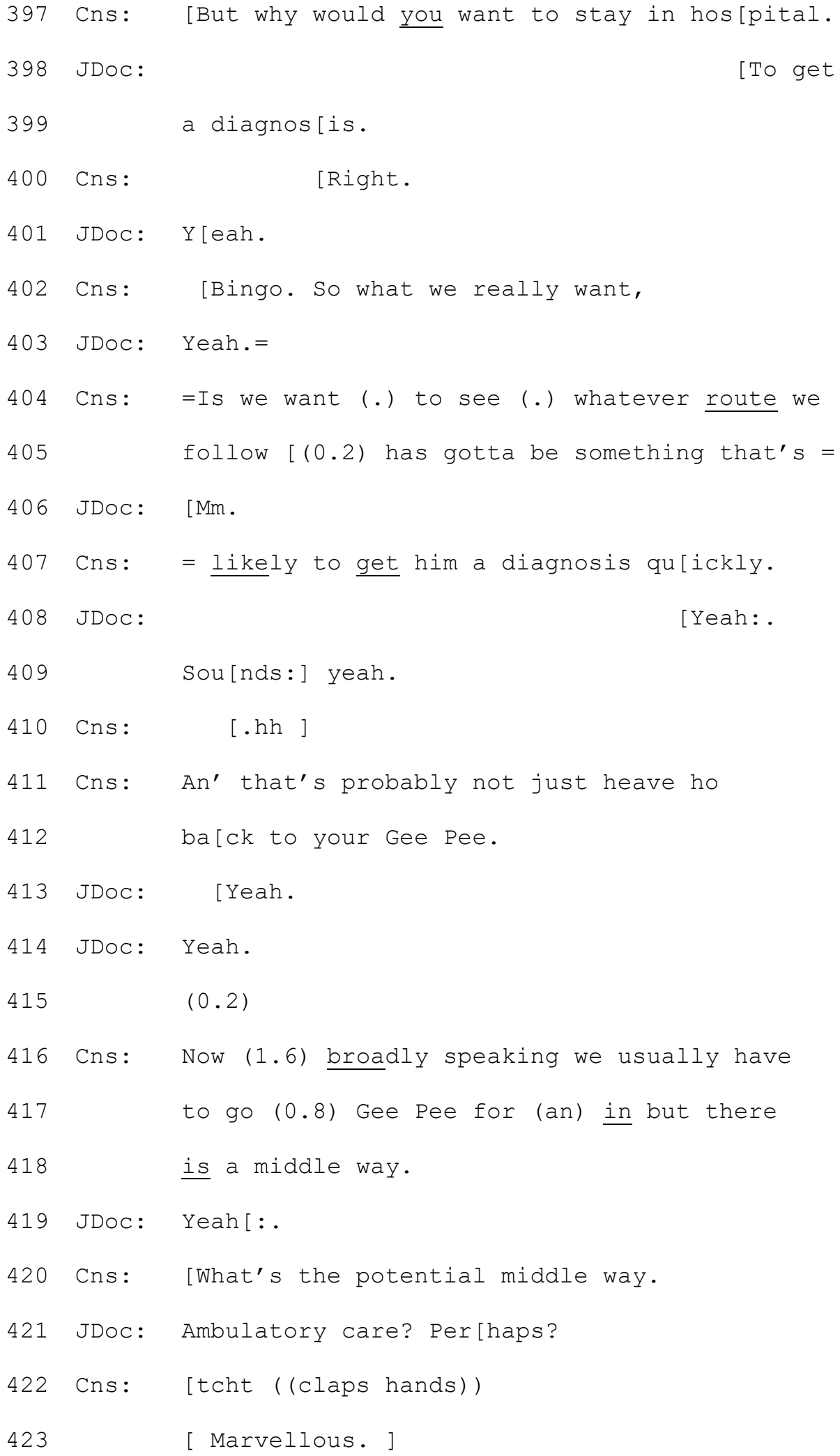


The extract above comes after a protracted sequence in which the consultant and junior doctor examine a scan, finally concluding that they can see no evidence of a kidney stone. Without this evidence they cannot refer the patient to the proposed clinical pathway and this results in a discussion of the patient's options. The first option raised by the consultant is to refer the patient to their GP. Interestingly the consultant shifts the focus of the interaction away from the clinical appropriateness of this action to what the junior doctor would want to do if she were the patient (line 383). This shifts the focus from medical practice, in which the consultant is more expert, to a focus on how the junior doctor would like to be treated herself, an arena of expertise of the junior doctor. The consultant's talk is produced in overlap with the junior doctor who appears to be building a case against referral to the GP based on concerns about the time it may then take to get a diagnosis (lines 381-382). The junior doctor states that she would want to be in hospital, finishing her turn with a laugh (line 385). The laughter can be seen as a response to the delicacy of indicating a preference for more specialist care than was originally mooted as a possible action (i.e. referral to the GP). The consultant pushes her to explain the reason for her preference responding with 'bingo' (line 402) when she suggests the patient needs a diagnosis (line 399). In contrast to the previous extract in which an established specialist clinical pathway was suggested, here there is a sense of circumventing medical systems, the creation of 'a middle way' (line 418), to provide optimal patient care. Here we have shown evidence of both exploitation and circumvention of medical pathways in the same case, illustrating the complexity involved in decisions about moving patients through A\&E.

\section{The role of epistemics in shaping interactions around medical disposal}

Of our 16 cases, in only one instance did a consultant examine the patient. Where the consultant has not seen the patient the junior doctor has more knowledge about the individual patient than the consultant. The consultant however is in a position of knowledge in relation to both formal medical 
and general experiential knowledge, as well as having an understanding of hospital procedures. It is useful here to employ Heritage's (2012) notion of epistemic status which he uses to consider the relative positioning of actors in recognising one another to be more or less knowledgeable concerning certain domains of knowledge. We would expect that as the focus of interactions between junior doctors and consultants shifts during discussions of patient cases this would be associated with the recognition of shifts in rights to contribute to the discussion relative to each actor's epistemic status.

Heritage (2012) also introduces the idea of epistemic stance which concerns how speakers position themselves in relation to epistemic status in and through the design of turns at talk. He argues the additional concept to epistemic stance is necessary because epistemic status can be dissembled by persons who deploy epistemic stance to appear more, or less, knowledgeable than they really are.

The following case illustrates the ways in which junior doctors design their talk according to their presumed epistemic rights. Here we can see that despite the consultant making a direct request to the junior doctor to present the next steps in the care of the patient, the subsequent presentation by the junior doctor is both tentative and mitigated and explicitly orientated to the judgement of the consultant.

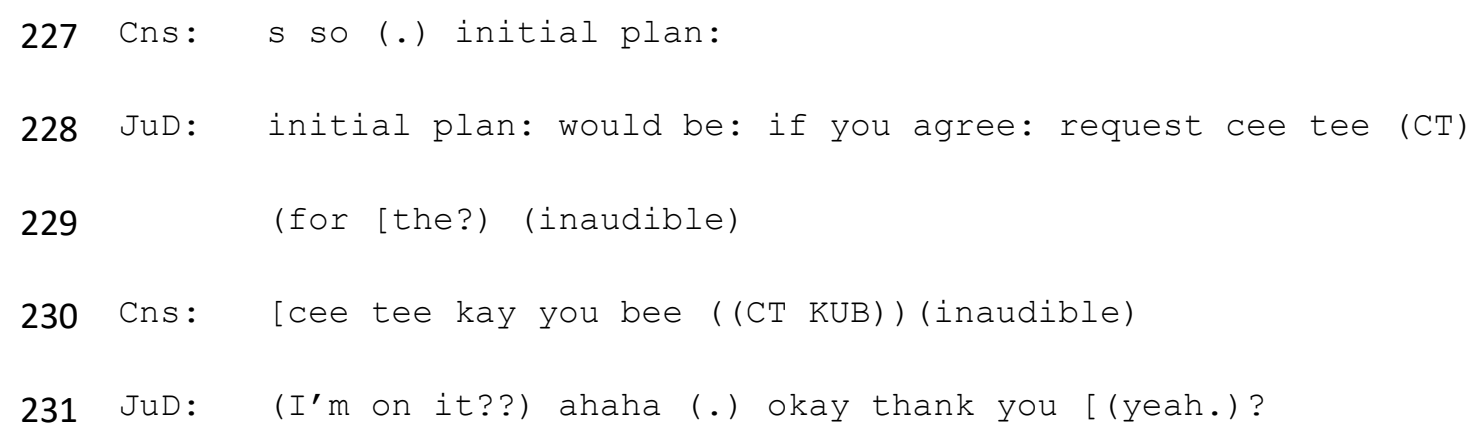


331 The move towards disposal is initiated by the consultant with 'so' (line 227) and the abbreviated

332 'initial plan'. The junior doctor hears this as a request for a plan, and even though this is presented 333 as an initial plan, (as opposed to a final plan), orientates to the delicacy of presenting a plan to the 334 consultant. This can be seen in the junior doctor's response of repeating the phrase 'initial plan', mirroring the slight stretch placed on 'plan' by the consultant, and then inserting 'if you agree' (line 228), all projecting hesitancy in claiming rights to make a definite statement about the proposed next steps. The consultant confirms the suggested scan, with some extra detail, and the junior moves to close the encounter with an appreciation (line 231). The interactional delicacy emanates from the fact that at this point in the interaction the consultant is more knowledgeable than the junior doctor, however the consultant employs epistemic stance to locate the junior doctor in a position to suggest what should happen next in the care of the patient.

We can also see an orientation to epistemics in the following example in which the junior doctor aligned herself with the institution of medicine in relation to the necessity for a scan. The extract concerned a man with severe back pain with a history of symptoms and treatment over a number of days culminating in him being brought into A\&E via ambulance, reporting he was barely able to stand and unable to walk. At the end of her presentation of the patient's symptoms the junior doctor reported a request from the patient's wife for an MRI scan and her reported response that this will only be done if deemed appropriate. The junior doctor finishes her turn by stating the patient's wife has recorded her name in her phone.

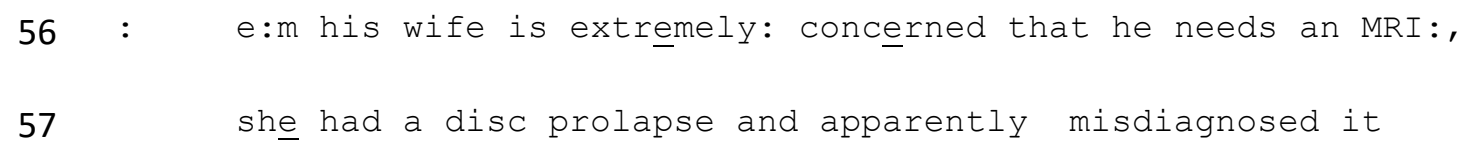




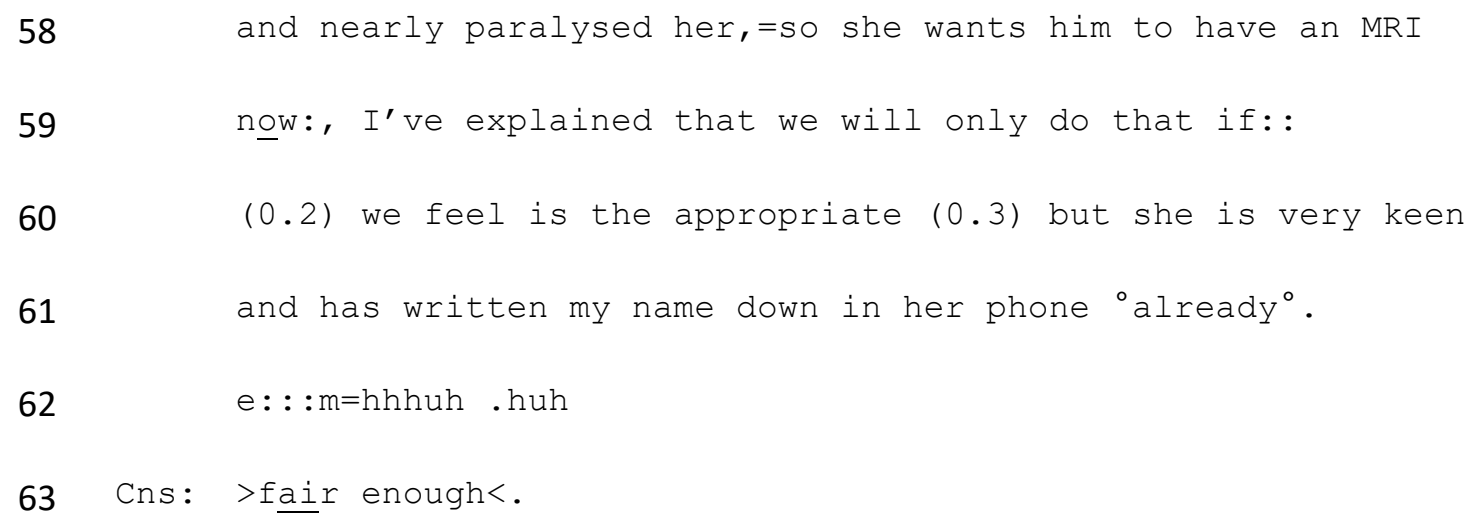

353 In lines 56-58 the wife's own medical experience of back pain was presented as justifying the request 354 for an MRI scan. The junior doctor then moved to report her response that 'we' will only do that if appropriate (line 59-60). In this way the junior doctor aligns herself with the medical profession in an account that demonstrates her moral accountability in relation to the use of scarce resources. She finishes her turn by indicating the pressure she feels based on the fact the wife has requested her name. This receives minimal uptake from the consultant in line 63, with a response of 'fair enough', produced rapidly. As we can see below, rather than directly accepting or refuting what the junior doctor has said about the need for a scan this is dealt with later in the interaction through the assertion that this is not a decision that will affect medical disposal, (in this case a referral), but rather will be addressed by the orthopaedic team following referral.

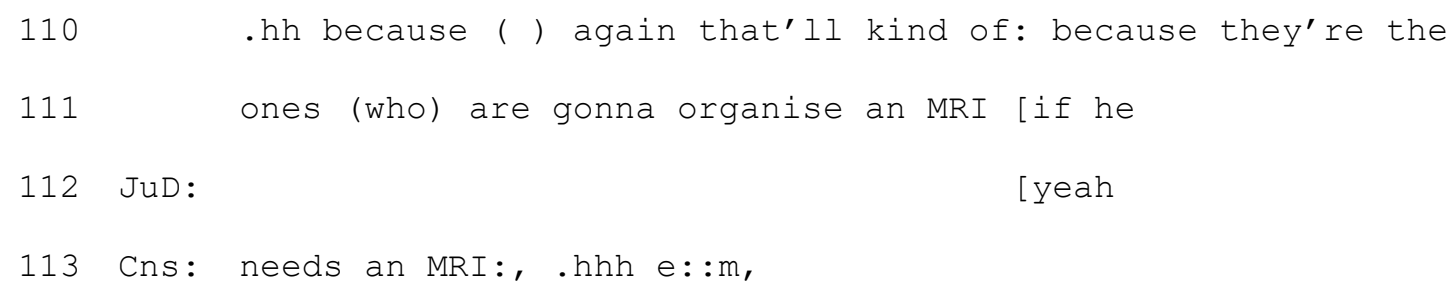




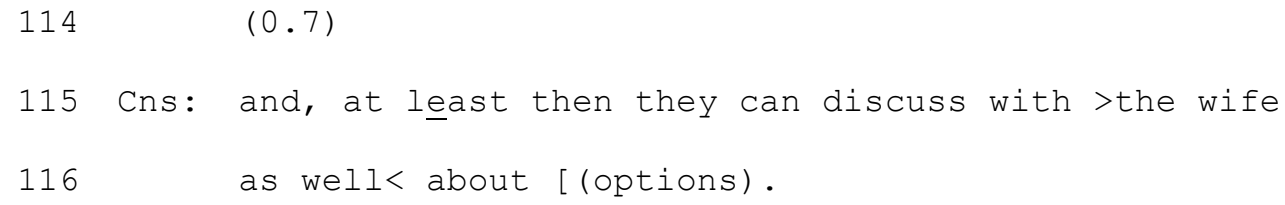

367 The revisiting of the necessity for an MRI scan and presentation of this in lines 111- 116 as a decision 368 to be taken by a specialist team can be seen as an assertion as to whom is in the best position to 369 order a scan. This interaction also acts to position A\&E as a department whose focus is on 370 throughput of patients (medical disposal), the actioning of which may not always require diagnostic 371 tests and treatment.

373 The function of A\&E in assessing and moving patients on as swiftly as possible is clearly made in the

374 following extract. Here the junior doctor presents the case of a woman who has suffered a

375 suspected stroke. Following an extended presentation by the junior doctor, taking one minute and 37614 seconds, the consultant agrees with the assessment of stroke. The junior doctor then proposes a 377 CT scan, the consultant however refuses and moves to referral, without a confirmatory scan.

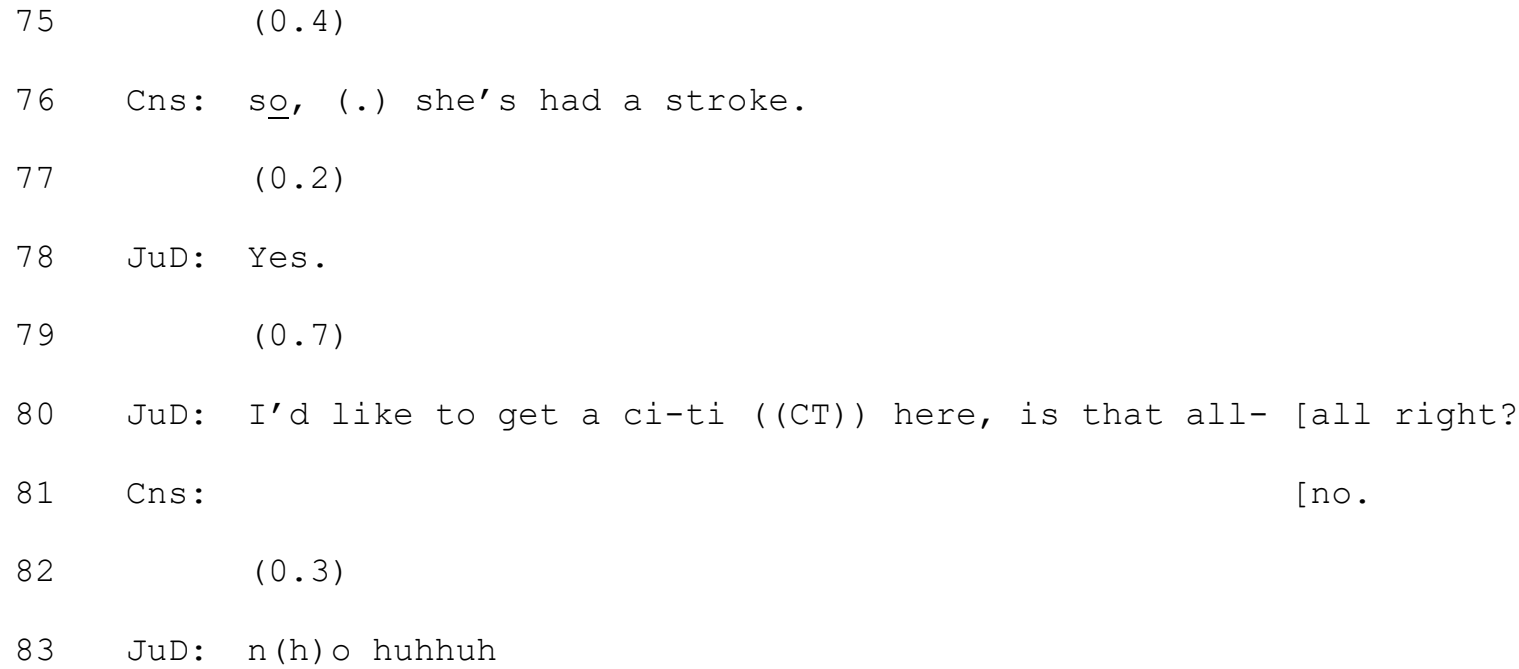


(.)

Cns: what does she nee: d?

$(0.5)$

JuD: WELL she needs a stroke assessment.

Cns: $\mathrm{n}[\mathrm{o.}]$

JuD: $\quad[s:] \quad e:: h$

Cns: more than that?,

(1.6)

JuD: mo[re than]

Cns: [what's her end] point today gonna be?

$(0.7)$

JuD: well, it's going to be: : :

$(0.4)$

Cns: where is she gonna be: (.) [this evening?

JuD : [on the stroke ward

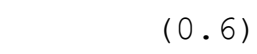




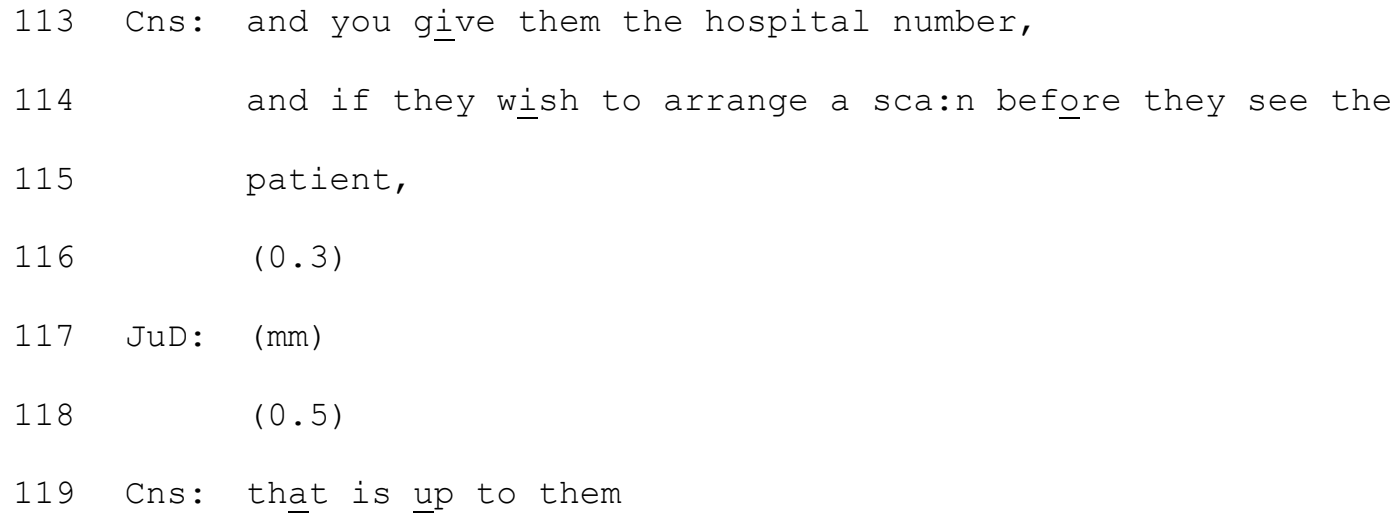

In contrast with Extract 3, there is no initial talk by the consultant to indicate or mark the possibility of withholding agreement to the junior doctor's request. The refusal, 'no', is delivered in overlap with the junior doctor's request in line 81 . This is received as interactionally problematic by the junior doctor who, after a pause in line 82 , repeats and extends the withholding of agreement with the utterance ' $n(h) o$ huhhuh'. We know from extensive analysis of agreements and disagreements in ordinary talk that disagreements tend to be delayed and / or mitigated and are treated as requiring an explanation (accountable) (Pomerantz 1984). Although this is an example of institutional talk we can see from the other data in our study that this is not how disagreement or misalignment is generally dealt with in talk between junior doctors and consultants. Although there is no issue in relation to the epistemic rights of the consultant to refuse the request, the junior doctor's response marks the delivery of withholding of agreement as interactionally problematic.

The consultant then presents a series of known answer questions, a pedagogic technique more closely associated with school teaching, to make the junior doctor vocalise a referral, not a scan, as the next step for the patient (lines 85-109). Although the consultant does not state the preferred course of action the way in which the interaction is organised and constructed, in particular the consultant's use of an extreme case formulation in lines 104-106, clearly indicates the expected outcome. The junior doctor appears to hear the refusal to authorise a scan and directive to make a 
referral as relating to the order in which these actions should be undertaken. This can be seen by

400 the use of the word 'first' in line 109, presenting the referral as part of a series of actions. The

401 consultant suggests the junior doctor may facilitate the scan by providing the specialist team with

402 the patient's hospital number so they can arrange a scan if they wish (Lines 113-119). This indicates

403 the fundamental concern is not whether the patient needs a scan but where responsibility for

404 ordering a scan lies.

In sharp contrast, in the following case a junior doctor concludes the presentation of the patient's symptoms and findings from a physical examination with an indicative diagnosis. This is followed by a collaborative completion alongside the consultant of a plan for medical disposal.

408

413 Prior to the indicative diagnosis the junior doctor provides an element of mitigation by saying he 414 'suspects' a stroke, presenting the diagnosis as 'top of his list'. Most notable here is the way the 
consultant's initial move is formulated (in line 47) which prepares the ground for the junior doctor's

416 collaborative completion (in line 48). In this way both the junior doctor and consultant present

417 themselves as competent in moving to a medical disposal.

418 The same junior doctor presented himself as a competent decision maker in another case by

419 repeatedly voicing his agreement to the suggested disposal presented by the consultant, arguably in

420 order to assert some level of ownership over it. He also sought to demonstrate his ability to work

421 independently and make decisions to discharge patients (medical disposal) without senior support.

422

423

Extract 11, case 10

424

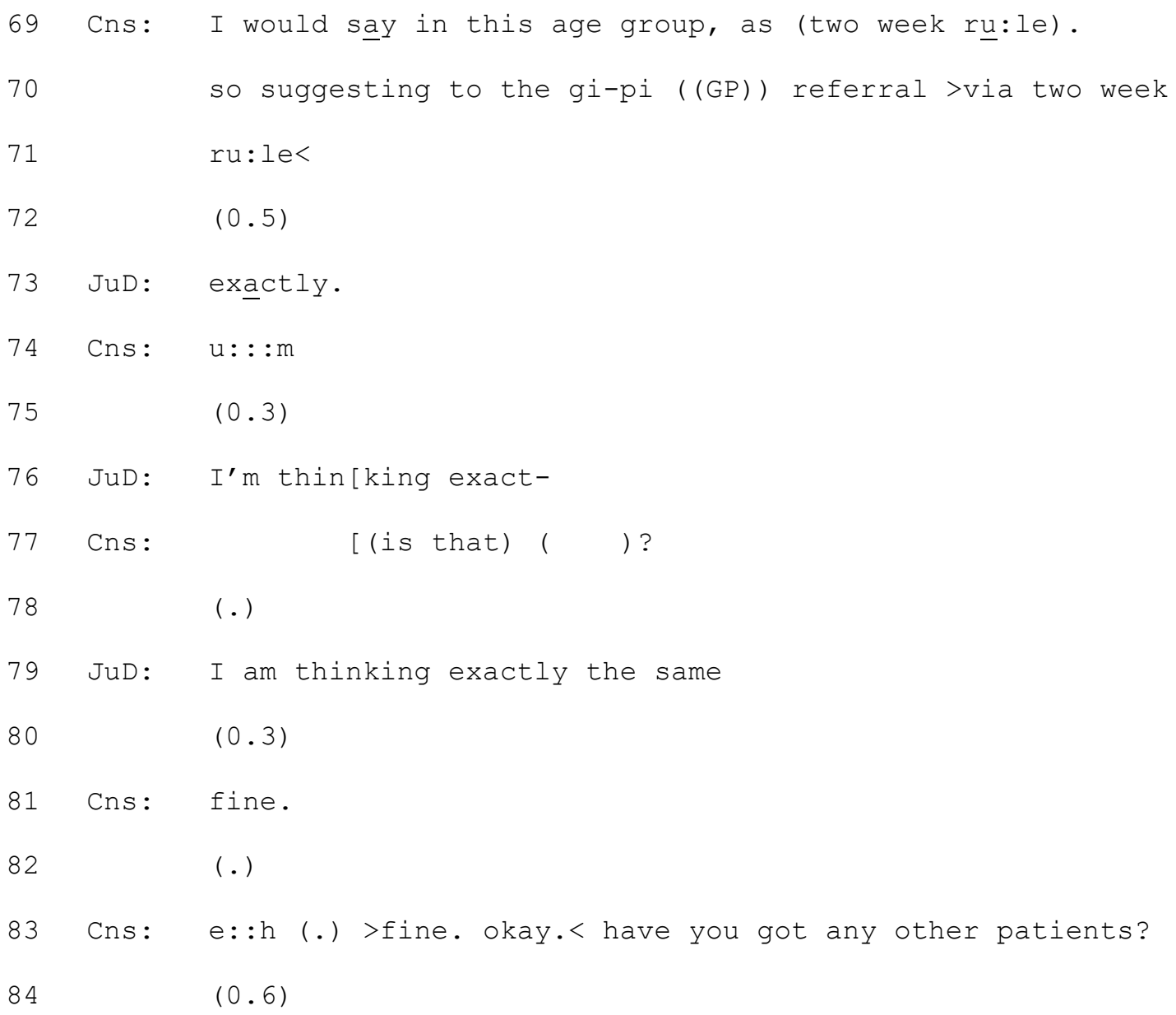




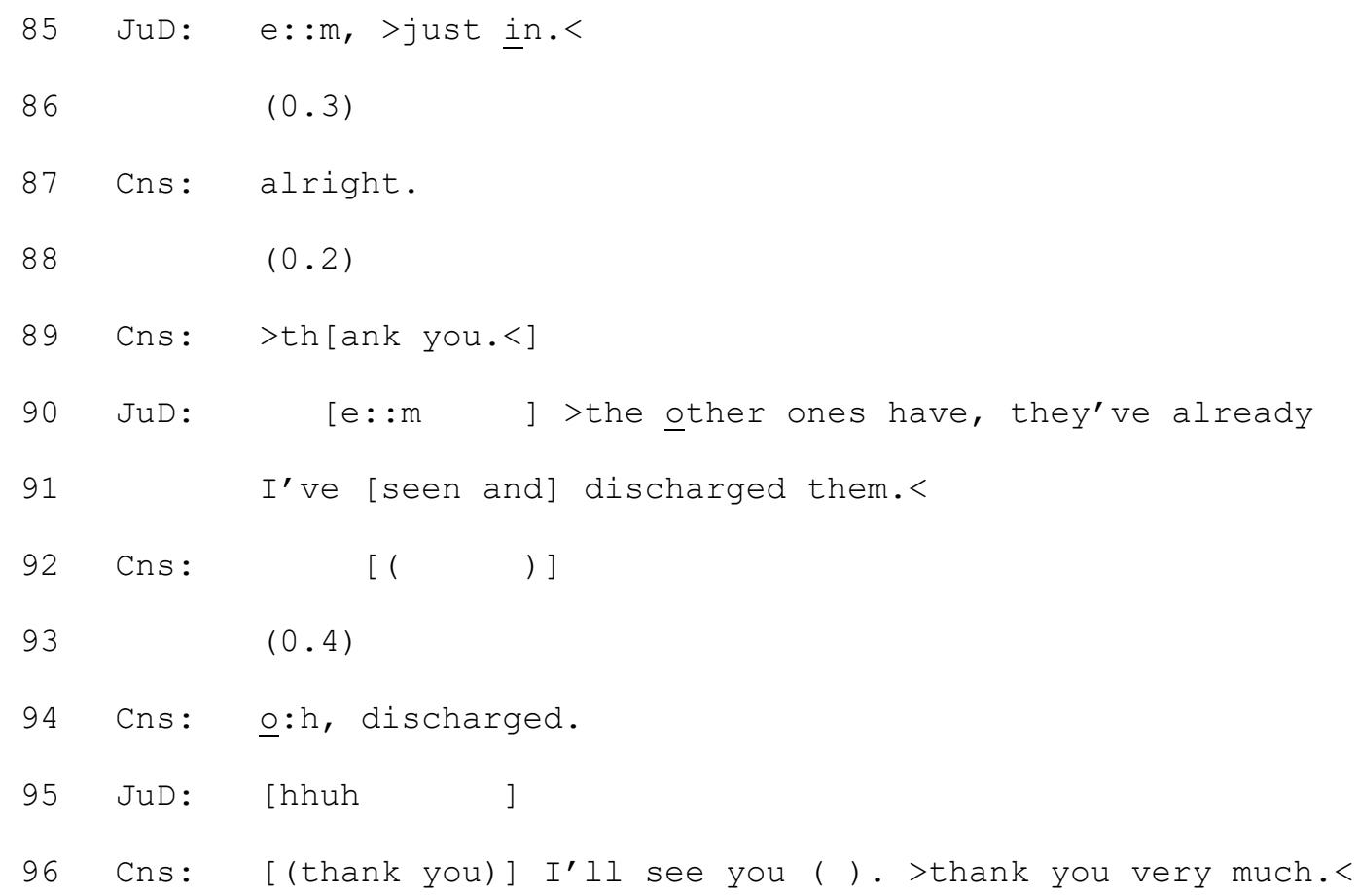

427 Although it is the consultant who presents the plan for medical disposal the junior doctor works to align in the strongest possible way through repeated attempts to vocalise that his thinking is in line with that of the consultant. This can be seen at lines 73 and 76 , and culminates with ' 1 am thinking exactly the same' on line 79. The repetition of 'exactly' by the junior doctor not only displays a

431 strong affiliation with the suggested action of the consultant but also works to present the junior 432 doctor as a competent decision maker. In lines 90-91 he enhances this presentation as a competent 433 decision maker by reporting that he has not only seen other patients, but discharged them without 434 seeking advice. The consultant marks this action as noteworthy through a pause in line 93, and 435 initiating his turn with 'oh' followed by repetition of the word 'discharged'. 
In this paper we have employed conversation analysis to provide a detailed analysis of the ways in which interactions between junior doctors and A\&E consultants unfold towards a decision to refer or discharge. This allowed for the presentation of the complexity of contingencies on decisions about the movement of patients through A\&E.

We know from work on the structure of medical consultation in primary care that the structure of consultations has an impact on patient participation (Robinson 2003). Building on Robinson's (2003) work, we argue that the structure of interactions between junior doctors and consultants affects the opportunities for junior doctors to present themselves as active decision makers. By focusing on the structure of the consultation we identified a pattern of interaction in which presentation of the patient's medical history and results of physical examination is done by the junior doctor, however in the majority of our cases the move towards a disposal and verbalisation of decisions was done by the consultant, generally through a summing up of what the junior doctor reported, moulded to fit a particular outcome. This was not always the case and we do have instances of collaborative interactions in this phase of the consultation.

We used Berg's (1992) concept of medical disposal to consider the ways in which patients' problems are remoulded and transformed in consultations between junior doctors and consultants into a solvable problem through what he refers to as "locally situated routines" Berg (1992: 173). Although most of our cases involved the consultant actively moulding and transforming the information provided by the junior doctor in order to present evidence for a particular disposal we are not suggesting that the interactions could be characterised as passive junior doctors being directed by decisive consultants. Rather, directives towards actions were generally presented somewhat tentatively as advice and included aspects of mitigation and we suggest that consultants are working with junior doctors to transform evidence from patients' accounts and physical examinations into an agreed medical disposal. Even in the case in which the consultant rejected the junior doctor's 
request for a scan there was agreement about the endpoint, the issue was the necessity for a scan prior to referral.

When considering how decisions are constructed we drew on the notion of epistemics. This allowed us to consider the relative position of junior doctors and consultants in interactions and the points at which possession of knowledge shifted. We argue that the ways in which the roles of junior doctor and consultant differ is a key factor to remain mindful of when examining decision making about medical disposal. Junior doctors are a training grade. Consultants, however, are responsible for supporting junior doctors in their development and learning while at the same time also for the safe and timely delivery of service. As consultants and junior doctors recognise one another to be more or less knowledgeable concerning certain domains of knowledge this affects how they design their turns at talk.

The analysis is limited to 16 cases from a single hospital site, however we conducted a detailed conversation analysis in order to demonstrate the complexity of interactions that determine patients' movement through A\&E. Although it was generally consultants who initiated a shift towards medical disposal we argue for the need to consider surrounding talk and instead see moves towards medical disposal as co-constructed. This was particularly evident where junior doctors asserted their views about medical disposal and demonstrated their competence to make decisions.

\section{Conclusions}

481 We argue for a nuanced understanding of what happens in A\&E departments in order to understand

482 the factors underlying patients' movement through A\&E. In the cases under consideration the 483 construction of medical disposal was also bound up with the potentially conflicting concerns of the 484 junior doctor's need to learn to act as an independent physician while ensuring the quality of 

how medical disposal is enacted in other hospital specialities and among other staff in order to further understand the movement of patients through hospital care.

488 
http://www.independent.co.uk/news/uk/home-news/a-e-patients-waiting-times-nhs-england-12hours-10546-per-cent-royal-college-emergency-medicine-a7962941.html (Accessed Nov 2017)

Adams E, Goyder C, Heneghan C, Brand L, Ajjawi R (2017) Clinical reasoning of junior doctors in emergency medicine: a grounded theory study Emergency Medicine Journal 34: 70-75

Berg M (1992) The construction of medical disposals Medical sociology and medical problem solving in clinical practice Sociology of Health \& IIIness 14: 151-180 conversation. Journal of Pragmatics, 41, 5, p.974-998. qualitative analysis of junior doctors' ward-based decision-making Journal of Vocational Education and Training 65: 402-421

Christmas E, Johnson I, Locker T (2013) The impact of 24h consultant shop floor presence on emergency department performance: a natural experiment Emergency Medicine Journal 30: 360362

Drew P, Chatwin J, Collins S (2001) Conversation analysis: a method for research into interactions between patients and health-care professionals Health Expectations 4: 58-70 Collins S, Drew P, Watt I. and Entwistle V. (2005) 'Unilateral' and 'bilateral' practitioner approaches in decision-making about treatment, Social Science \& Medicine, 61, 12, 2611-27. 
Derrick S, Badger B, Chandler J, Nokes T, Winch G (2006) The training/service continuum: exploring the training/service balance of senior house officer activities Medical Education 40: 355-362

512 European Working Time Directive (http://www.bma.org.uk/support-at-work/ewtd/ewtd-juniors)

513 Heritage, J. (2012) Epistemics in action: action formation and territories of knowledge, Research on

514 Language and Social Interaction, 45, 1, 1-29.

515 Jefferson, G. (2004) Glossary of transcript symbols with an Introduction. In Lerner, G.H. (ed.)

516 Conversation Analysis: Studies from the First Generation. Philadelphia: John Benjamins.

517 Kings Funds (2017) https://www.kingsfund.org.uk/projects/urgent-emergency-care/urgent-and-

518 emergency-care-mythbusters. Accessed 21/06/17

519 Pomerantz, A. (1984) Agreeing and Disagreeing with Assessments: Some Features of

520 Preferred/Dispreferred Turn Shapes. In: J. M. Atkinson \& J. Heritage (Eds), Structures of Social

521 Action: Studies in Conversation Analysis (pp. 57-101). Cambridge: Cambridge University Press

522 Potter, J. \& Shaw, C. (2018) The virtues of naturalistic data. In U. Flick (Ed.) The Sage handbook of

523 qualitative data collection (pp. 182-199). London: Sage

524 Rapley T (2008) Distributed decision making: the anatomy of decisions-in-action. Sociology of Health

525 and IIIness 30: 429-444.

526 Robinson, J.D. (2003) An interactional structure of medical activities during acute visits and its

527 implications for patients' participation. Health Communication, 15, 27-59.

528 Sen A, Hill D, Menon D, Rae F, Hughes H, Roop R (2012) The impact of consultant delivered service in 529 emergency medicine: the Wrexham Model Emergency Medicine Journal 29: 366-371

530 Stevenson FA, Gibson W, Pelletier C, Chrysikou V, Park S (2015) Reconsidering 'ethics' and 'quality' in 531 healthcare research: the case for an iterative ethical paradigm BMC Medical Ethics 16(1). 
532 Stivers, T. (2007) Prescribing under Pressure: Parent-Physician Conversations and Antibiotics.

533 Oxford: Oxford University Press.

534 Heritage and D.W. Maynard, (Eds) (2006). Communication in Medical Care: Interaction between

535 Primary Care Physicians and Patients. Cambridge: Cambridge University Press, Collins

536 Toerien, M., Shaw, R. and Reuber, M. (2013) Initiating decision-making in neurology consultations:

537 'recommending' versus 'option-listing' and the implications for medical authority Sociology of Health

538 \& IIIness $35,6,873-890$.

539 Stevenson, F.A., Barry, C.A., Britten, N. and Barber, N. et al. (2000) Doctor-patient communication

540 about drugs: the evidence for shared decision making, Social Science \& Medicine, 50, 6, 829-40 
542 FIGURE 1: Transcription symbols used in the analysis

543

544 : $\quad$ Extended vocal sound. Multiple colons indicate further extension

545 (0.2) Pause in tenths of a second

546 (.) micro pause

$547 \quad><\quad$ rapid speech

$548 \quad ? \quad$ Upward intonation

549 @ quiet speech

550 , continuing intonation

$551=$ latched talk

552 (( )) text between double brackets gives descriptions of action or clarifications of phonetic

$553 \quad$ meaning

$554 \quad$ _ $\quad$ Underling text used to denote forms of emphasis

555 () Single brackets used to indicate sections that were hard to hear or not hearable

$556 ? \quad$ Upward intonation

557 